\title{
Selection of Military and Local Integration Emergency Material Procurement Suppliers Based on Set Pair Analysis Method
}

\author{
Yuanli Zhao, Yunpeng Xiao, Bojian Yu \\ Department of Aviation Oil and Materials \\ Air force Service College \\ Xuzhou Jiangsu, 221000 \\ 493907453@qq.com; 563199409@qq.com; 785048332@qq.com
}

\begin{abstract}
In this paper, the military and local integration emergency material procurement suppliers ideal evaluation index system was constructed, the set pair analysis method was introduced, the contracted matrix of index system was constructed and the connection degree index synthesis was done based on the sample evaluation index through statistical analysis, expert evaluation, function calculation and other methods. Then the degree of identity, diversity and contrary of emergency material procurement suppliers evaluation index were calculated. At last, the evaluation result sorted and the foundation of military and local integration emergency material procurement suppliers selection was given.
\end{abstract}

Key words-military and local intergration; emergency material procurement; suppliers selection; set pair analysis

\section{INTRODUCTION}

The military and local integration emergency material procurement means a organization form which was projected, concerted and controlled by military and local material procurement organization on transportation, storage, distribution, technical support and other factors involved in the emergency material support process to insured the efficient and smooth running of military and local integration emergency material procurement [1]. The research aboard started earlier on this subject, America and Japan have taken the lead for a long time. The research inland have started after "Wenchuan" earthquake, Zhu Bidun [2] and Zhang Xiaohua [3] have researched the strategy and model of emergency material procurement in China, expounded the monitoring and support mechanism by emergency material procurement location model.

If the storage of military can not meet the material need, local material would be the best choice, and the selection of suppliers would be a key points which we must face, and this will influence the whole situation. There were many methods used in this subject, such as analytic hierarchy process (AHP), projection pursuit evaluation model and so on. Most of these methods need a lot of precise data, however there were many uncertainties in the selection of suppliers, and expert prefer to give fuzzy evaluate. So, a new method needs to be used in this subject to solve this problem. In this paper, the set pair analysis method was produced, and a new foundation was given through the construction of evaluation system.

\section{SYSTEM CONSTRUCTION}

\section{A. Construction Basis}

In the course of military and local integration emergency material procurement suppliers selection, for the short procurement time, high procurement quality, large procurement quantity, contradictory procurement method and rules, the 4 aspects follows need to be pay attention:

1) Procurement efficiency support: In the course of suppliers selection, emergency material support was the first point which need to be met. And this could be reflected in many aspects such as service timely, quality guarantee and so on. For the time requirement, promptness and safety came to be the main aspects to be considered [4].

2) Procurement organization support: The selection of suppliers in military and local intergration emergency material procurement involved a lot of aspects, there were many problems in organize and command in this mode. So obey command, coordinate conveniencely, order smoothly came to be another main foundation.

3) Procurement resource support: Which was formed by hardware preparation and software preparation. Hardware preparation included preparation of facility and equipment, storage of emergency material and so on. Software preparation included preparation of personnel and information, presumation of emergency scenes, formulation of emergency measures and so on [5].

4) Procurement cost reasonabl: Emergency material procurement has low economy, but it doesn't mean no economy. So, saving the cost was still an important index in the course of emergency material procurement.

\section{B. Construction Principle}

There were 4 principles as follows need to be pa attention in the course of emergency material procurement suppliers selection [6]:

1) Adaptability and variability: The setting of evaluation index system was a metabolic and developmental system engineering, the market was changing, the suppliers were 
developing, so the requirement was changing too. So, adaptability was the principle we should observe all the time.

2) Systematicness and comprehensiveness: To ensure the integrity of evaluation index content, evaluation index system should involve the main index which had high influence, obey the evaluation standards, methods, procedure by the point of systematicness and comprehensiveness, then choose the supplier which could meet all the conditions.

3) Simplicity and scientificity: Scientificity was the premise of emergency material procurement suppliers selection. In the course of evaluation index system construction, the scale of system should be suitable, the index should not too rough or too detailedness. The simplicity and scientificity principle should be ensured from begin to the end.

4) Flexibility and operability: The evaluation system had a lot of index, the reliability of evaluation result and flexibility of calculation should both be noticed, only this can make the index system have full feasibility.

\section{Index System}

The index system was as follows in figure 1 based on the Construction basis and Construction principle in the course of military and local integration emergency material procurement suppliers selection.

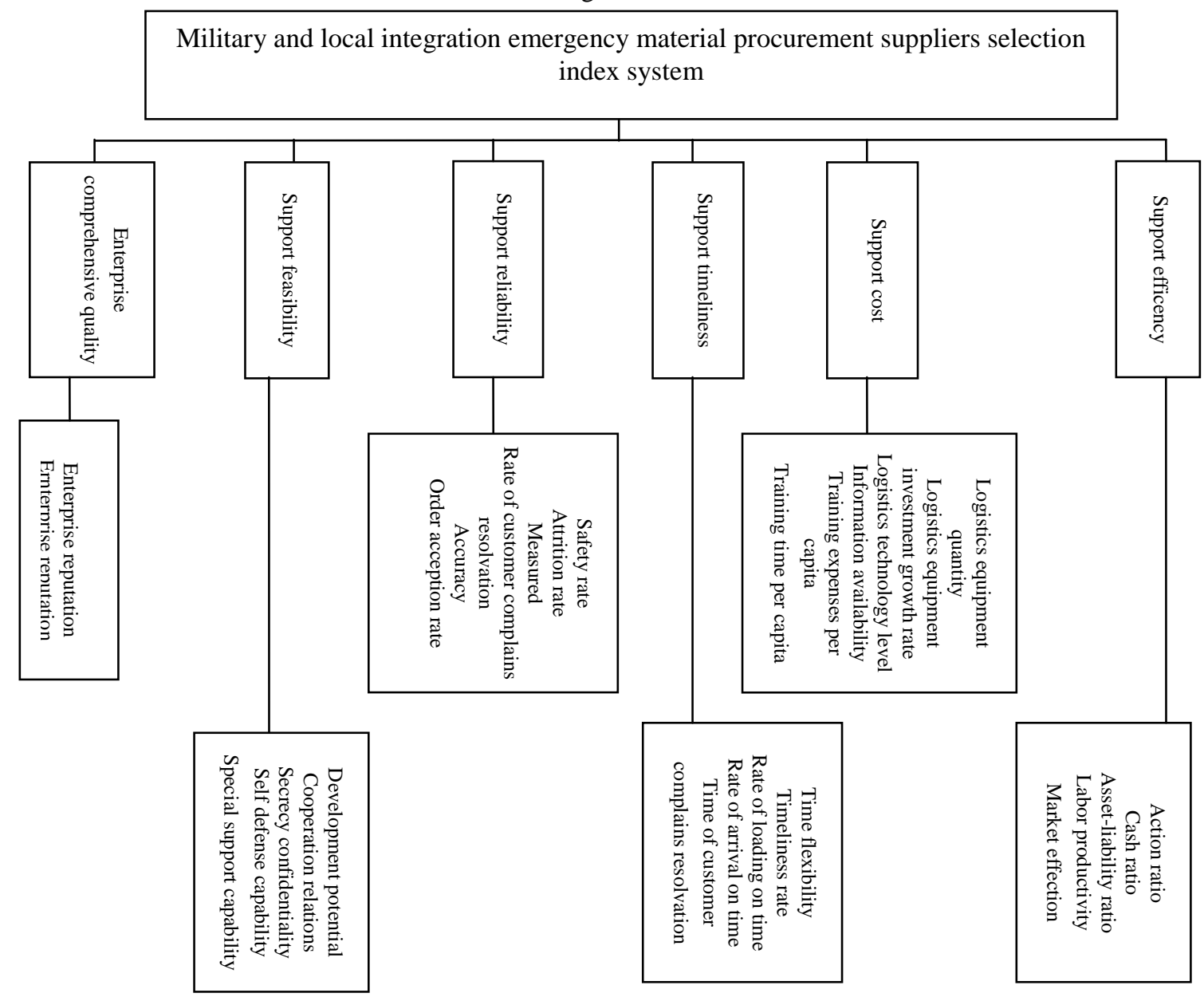

Figure 1. Figure 1 Military and local intergration emergency material procurement suppliers selection index system

\section{SUPPLIERS SELECTION}

\section{A. Theory Research}

Set pair analysis method was a new system analysis method raised by Zhao Keqin [7], it put certainty and uncertainty together to handle comprehensive integration problems, and

In this formula, $\mu$ means evaluation object, $\mathrm{a}, \mathrm{b}, \mathrm{c}$ means the degree of identity, diversity and contrary. i means coefficient of diversity respectively, $\mathrm{i} \in[-1,1] ; \mathrm{j}$ means coefficient of contrary respectively, $\mathrm{j} \in[-1,1], \mathrm{j}=-1$ in common. researched the characteristics of index in identity, contrary and connection aspects. Set pair meant put two collections which had some relations into a pair, then integrate certainty with uncertainty by a certain formula as formula (1).

$$
\mu=a+b i+c j
$$

Connection has the work to describe certainty and uncertainty of two collections in pair quantification under a certain background. The three index satisfy the normalization condition, it means $\mathrm{a}+\mathrm{b}+\mathrm{c}=1$. 


\section{B. Ideal index evaluation construction}

Note the military and local integration emergency material procurement suppliers selection index system as $\mathrm{G}=(\mathrm{S}, \mathrm{E}, \omega$, $\mathrm{X})$. In this formula, $\mathrm{S}=\left\{S_{1}, S_{2}, \ldots, S_{M}\right\}$ means suppliers in this evaluation course, $S_{\kappa}$ means the supplier numbered $\kappa$. $\mathrm{E}=\left\{e_{1}, e_{2}, \ldots, e_{n}\right\}$ means evaluation index, $e_{\gamma}$ means the index numbered $\gamma$, in this matrix $\mathrm{E}_{1}$ means efficient index, $\mathrm{E}_{2}$ means cost index. $\varpi=\left(\varpi_{1}, \varpi_{2}, \ldots, \varpi_{n}\right)$ means index weighted value, $\varpi_{r}$ means the weighted value of $e_{\gamma}$, $\sum_{r=1}^{n} \varpi_{r}=1, \varpi>0 . X=\left(x_{\kappa \gamma}\right)_{m \times n}$ means decision matrix, $x_{\kappa \gamma}$ means the index value of $e_{\kappa}$. In order to analysis all the objects, the optimal evaluation collection $\mathrm{U}=\left(u_{1}, u_{2}, \ldots, u_{n}\right)$ and the worst collection $V=\left(v_{1}, v_{2}, \ldots, v_{n}\right)$ was gotten from the evaluation value of all index. In these collections $u_{\gamma}, v_{\gamma}$ means the optimal evaluation and the worst evaluation. The selection of comparison interval came down to the type of index, for $e_{r} \in \mathrm{E}_{1}$, comparison interval was $\left[v_{r}, u_{r}\right]$, for the $e_{r} \in \mathrm{E}_{2}$, comparison interval was $u_{r}, v_{r}$ which constituted comparison interval $[V, U]$ with the worst evaluation collection.

\section{Construction of Connection Matrix}

For the efficiency index $e_{\gamma} \in \mathrm{E}_{1}$ :

$$
\left[\frac{x_{\kappa \gamma}}{u_{\gamma}+v_{\gamma}}, \frac{x_{\kappa \gamma}{ }^{-1}}{u_{\gamma}^{-1}+v_{\gamma}^{-1}}\right] \in[0,1]
$$

In the comparison interval $\left[v_{\gamma}, u_{\gamma}\right]$, and they showed the approximation degree, when the value went high, they were closer. In the meanwhile, the closer $x_{\kappa \gamma}$ and $v_{\gamma}$ went, $x_{\kappa \gamma}$ and $u_{\gamma}$ were more far. We make the identity degree $a_{\kappa \gamma}$ and contrast degree $c_{\kappa \gamma}: a_{\kappa \gamma}=\frac{x_{\kappa \gamma}}{u_{\gamma}+v_{r}}, c_{\kappa \gamma}=\frac{u_{\gamma v_{\gamma}}}{\left(u_{\gamma}+v_{\gamma}\right) x_{\kappa \gamma}}$ in the pair $x_{\kappa \gamma}, u_{\gamma}$.

Defined the diversity degree $b_{\pi \gamma}$ of pair $\left\{x_{\kappa \gamma}, u_{\gamma}\right\}$ from formula (1) as followed:

$$
b_{r k}=1-\left(a_{\kappa \gamma}+c_{\kappa \gamma}\right)=\frac{\left(u_{\gamma}-x_{\kappa \gamma}\right)\left(x_{\kappa \gamma}-v_{\gamma}\right)}{\left(u_{r}+v_{\gamma}\right) x_{\kappa \gamma}}
$$

From the analysis above, defined the connection degree of of pair $\left\{x_{\kappa \gamma}, u_{\gamma}\right\}$ for efficiency index as followed: $\mu\left(x_{\kappa \gamma}, u_{\gamma}\right)=\frac{x_{\kappa \gamma}}{u_{\gamma}+v_{\gamma}}+\frac{\left(u_{\gamma}-x_{\kappa \gamma}\right)\left(x_{\kappa \gamma}-v_{\gamma}\right)}{\left(u_{\gamma}+v_{\gamma}\right) x_{\kappa \gamma}} i+\frac{u_{\gamma} v_{\gamma}}{\left(u_{\gamma}+v_{\gamma}\right)} j$

For the cost index $e_{\gamma} \in \mathrm{E}_{2}$, defined the connection of pair $\left\{\chi_{\kappa \gamma}, u_{\gamma}\right\}$ as followed in comparison interval:

$\mu\left(x_{\kappa \gamma}, u_{r}\right)=\frac{u_{\gamma} v_{\gamma}}{\left(u_{r}+v_{r}\right) x_{\kappa \gamma}}+\frac{\left(u_{\gamma}-x_{\kappa \gamma}\right)\left(x_{\kappa \gamma}-v_{\gamma}\right)}{\left(u_{\gamma}+v_{\gamma}\right) x_{\kappa \gamma}} i+\frac{x_{\kappa \gamma}}{u_{\gamma}+v_{\gamma}} j$

United the formula (3) and (4) we could get that:

$\mu_{\chi_{\kappa \gamma}}=a_{\kappa \gamma}+b_{\kappa \gamma} i+c_{\kappa \gamma} j$

\section{Connection Degree Index Composition and Evaluation Result Sorting}

The single connection degree could only show the approximation degree for the supplier $s_{\kappa}$ and index $e_{\gamma}$. For the different importance of every index, weight coefficient should be introduced to indicate the importance of them, then the comprehensive connection degree will of $\left\{s_{\kappa}, \mathrm{U}\right\}$ in comparison interval will be reached as formula (6):

$$
\mu_{\kappa}=\alpha_{\kappa}+b_{\kappa} i+c_{\kappa} j
$$

In this formula:

$$
a_{\kappa}=\sum_{r=1}^{n} \varpi_{\gamma} a_{\kappa r}, b_{\kappa}=\sum_{r=1}^{n} \varpi_{r} b_{k r}, c_{\kappa}=\sum_{r=1}^{n} \varpi_{r} c_{k r}
$$

$\omega_{\gamma}$ means the weight of index $e_{\gamma}$. For the relativity of $a_{\kappa}$ (certainty to optimal evaluation collection) and $c_{\kappa}$ (uncertainty to optimal evaluation collection), defined relativity approximation value $\gamma_{\kappa}$ between $s_{\kappa}(k=1,2, \ldots, m)$ and $\mathrm{U}$ as followed:

$$
\gamma_{\kappa}=\frac{\alpha_{\kappa}}{\alpha_{\kappa}+c_{\kappa}}
$$

The bigger the value of $\gamma_{\kappa}$ was, the closer $s_{\kappa}$ and $\mathrm{U}$ were, and the comprehensive level is higher of suppliers. So the relativity approximation value $\gamma_{K}$ could be the basis for the selection of military and local integration emergency material procurement suppliers.

\section{APPLICATION}

If there was an assumption that "SARS" burst in some days, and the medicine, respiration, protection could not meet the demand in this condition, emergency materials procurement 
became the most important problem need to be settled. And in this problem, suppliers selection became the first problem need to be faced.

Assumption that there were four suppliers could meet the demands, the index system was constructed based on the content above. And the index value was get through statistics, expert estimate, function calculation and other methods. In the course of index selection, chose a class index which had important influence based on ABC analysis method, such as enterprise reputation, symbiosis, confidentiality sense and so on. Then, got the weighted value by AHP method as: $(0.2021$, 0.1143, 0.1068, 0.1018, 0.0708, 0.1556, 0.0626, 0.0684, 0.0472, $0.0749)$. Got the pair identity degree $\alpha_{\kappa \gamma}$, contrary degree $c_{\kappa \gamma}$ and diversity degree showed in table 2 through formula (3), (4), (5).

TABLE I. IDENTITY DEGREE AND CONTRARY DEGREE OF SUPPLIERS EVALUATION INDEX

\begin{tabular}{|c|c|c|c|c|c|c|c|c|}
\hline \multirow[b]{2}{*}{ Index } & \multicolumn{2}{|c|}{ Supply 1} & \multicolumn{2}{|c|}{ Supply 2} & \multicolumn{2}{|c|}{ Supply 3} & \multicolumn{2}{|c|}{ Supply 4} \\
\hline & $\begin{array}{l}\text { Identity } \\
\text { degree }\end{array}$ & $\begin{array}{c}\text { Contrary } \\
\text { degree }\end{array}$ & $\begin{array}{l}\text { Identity } \\
\text { degree }\end{array}$ & $\begin{array}{l}\text { Contrary } \\
\text { degree }\end{array}$ & $\begin{array}{l}\text { Identity } \\
\text { degree }\end{array}$ & $\begin{array}{l}\text { Contrary } \\
\text { degree }\end{array}$ & $\begin{array}{l}\text { Identity } \\
\text { degree }\end{array}$ & $\begin{array}{c}\text { Contrary } \\
\text { degree }\end{array}$ \\
\hline Enterprise reputation & 0.438 & 0.438 & 0.492 & 0.492 & 0.463 & 0.463 & 0.492 & 0.492 \\
\hline Symbiosis & 0.529 & 0.529 & 0.471 & 0.471 & 0.529 & 0.529 & 0.471 & 0.471 \\
\hline Confidentiality sense & 0.396 & 0.396 & 0.392 & 0.392 & 0.404 & 0.404 & 0.404 & 0.404 \\
\hline Support capability & 0.452 & 0.452 & 0.48 & 0.48 & 0.548 & 0.548 & 0.48 & 0.48 \\
\hline Safety rate & 0.498 & 0.498 & 0.531 & 0.531 & 0.469 & 0.469 & 0.469 & 0.469 \\
\hline Accuracy & 0.535 & 0.535 & 0.486 & 0.486 & 0.465 & 0.465 & 0.498 & 0.498 \\
\hline Promptness & 0.529 & 0.529 & 0.471 & 0.471 & 0.498 & 0.498 & 0.529 & 0.529 \\
\hline On-time rate & 0.498 & 0.498 & 0.529 & 0.529 & 0.529 & 0.529 & 0.471 & 0.471 \\
\hline $\begin{array}{c}\text { Time of customer } \\
\text { complains resolvation }\end{array}$ & 0.286 & 0.286 & 0.571 & 0.571 & 0.429 & 0.429 & 0.714 & 0.714 \\
\hline $\begin{array}{c}\text { Logistics technology } \\
\text { level }\end{array}$ & 0.471 & 0.471 & 0.529 & 0.529 & 0.498 & 0.498 & 0.529 & 0.529 \\
\hline
\end{tabular}

At last, got the set pair analysis result showed in table 3 by the comprehensive connection of suppliers through formula (6) and (7). From the table 3 we could get the evaluation result like that supplier $1>$ supplier $3>$ supplier $2>$ supplier 4 . That is to say, the supplier 1 is the best one we should choose in military and local integration emergency material procurement.

TABLE II. RESULT OF SET PAIR ANALYSIS

\begin{tabular}{|c|c|c|c|}
\hline Supplier & $a_{\kappa}$ & $c_{\kappa}$ & $\gamma_{\kappa}$ \\
\hline Supplier 1 & 0.5317 & 0.4704 & 0.5306 \\
\hline Supplier 2 & 0.5103 & 0.4869 & 0.5117 \\
\hline Supplier 3 & 0.5148 & 0.4816 & 0.5167 \\
\hline Supplier 4 & 0.5081 & 0.4913 & 0.5084 \\
\hline
\end{tabular}

\section{CONCLUSION}

In this paper, the identity, diversity and contrary quantitative analysis was applied in military and local integration emergency material procurement suppliers selection based on set pair analysis method, through the construction of evaluation index system connection matrix and connection degree index composition. The degree of identity, diversity and contrary was counted, then the scientific evaluation result sorting provide a strong foundation to suppliers selection.

After all, suppliers evaluation and selection were important parts and paths for military and local integration emergency material procurement system. Set pair analysis method could combine and optimize all the index under the direction of dynamic alliance, military and local integration thought. Then form a comprehensive security entity to make the construction of military and local integration emergency material procurement system better, and at last solve outstanding issues in military and local integration emergency material procurement.

\section{REFERENCES}

[1] Li Yongde. Institution research on military and local intergration emergency material procurement $[\mathrm{J}]$. Chinese logistics and procurement, 2008 (6): 26-28

[2] Zhu Bidun. Strategies discussed of emergency material procurement in China [J]. Enterprise leader, 2009 (2): 67-68

[3] Zhang Xiaohua. Analysis of emergency material procurement suppliers management [J]. Economy research, 2010 (5): 138-140

[4] Zhu Wei, Hu Anhui. Application of AHP in emergency logistics project selection [J]. Logistics technique, 2005 (3): 45-47

[5] Jin Xiuman. Conbination of military and local intergration in military logistics area [J]. Chinese market, 2009 (23): 14-15

[6] He Runmin, Zhang Jianyun. Generalized water environmental carrying capacity evaluation on set pair analysis [J]. Water scientific advances, 2007 (9): 730-735

[7] Zhao Keqin. Preliminary analysis of set pair analysis [M]. Hangzhou: Zhejiang science and technology press. 2000: 108-122 